\title{
Evidence for more cost-effective surveillance options for bovine spongiform encephalopathy (BSE) and scrapie in Great Britain
}

BA Wall ${ }^{1}$, ME Arnold 2 , D Radia, W Gilbert ${ }^{1}$, A Ortiz-Pelaez 2 , KD Stärk ${ }^{1}$, E Van Klink ${ }^{3}$, J Guitian ${ }^{1}$

1. Royal Veterinary College, London, United Kingdom

2. Animal and Plant Health Agency, Weybridge, United Kingdom

3. University of Bristol, United Kingdom

Correspondence: Ben Ari Wall (bwall@rvc.ac.uk)

Citation style for this article:

Wall BA, Arnold ME, Radia D, Gilbert W, Ortiz-Pelaez A, Stärk KD, Van Klink E, Guitian J. Evidence for more cost-effective surveillance options for bovine spongiform encephalopathy (BSE) and scrapie in Great Britain. Euro Surveill. 2017;22(32):pii=30594. DOI: http://dx.doi.org/10.2807/1560-7917.ES.2017.22.32.30594

Article submitted on 27 October 2016 / accepted on 15 March 2017 / published on 10 August 2017

Transmissible spongiform encephalopathies (TSEs) are an important public health concern. Since the emergence of bovine spongiform encephalopathy (BSE) during the 1980 s and its link with human CreutzfeldtJakob disease, active surveillance has been a key element of the European Union's TSE control strategy. Success of this strategy means that now, very few cases are detected compared with the number of animals tested. Refining surveillance strategies would enable resources to be redirected towards other public health priorities. Cost-effectiveness analysis was performed on several alternative strategies involving reducing the number of animals tested for BSE and scrapie in Great Britain and, for scrapie, varying the ratio of sheep sampled in the abattoir to fallen stock (which died on the farm). The most cost-effective strategy modelled for BSE involved reducing the proportion of fallen stock tested from $100 \%$ to $75 \%$, producing a cost saving of caGBP 700,000 per annum. If $50 \%$ of fallen stock were tested, a saving of ca GBP 1.4 million per annum could be achieved. However, these reductions are predicted to increase the period before surveillance can detect an outbreak. For scrapie, reducing the proportion of abattoir samples was the most costeffective strategy modelled, with limited impact on surveillance effectiveness.

\section{Introduction}

Bovine spongiform encephalopathy (BSE) is a prion disease of cattle, first identified in 1986 in Great Britain (GB) (GB refers to England, Wales and Scotland, whereas the United Kingdom (UK) also includes Northern Ireland. This study was based on GB-level data, however some of the data referred to were recorded at UK level). The epidemic in GB reached its peak in 1992 with ca 37,000 BSE cases [1], evolving into a public health crisis when it was linked to a human neurodegenerative condition, variant Creutzfeldt-Jakob disease (vCJD), in 1996. To date, a total of 229 deaths from $v C J D$ have been recorded, of which 177 were in the UK $[2,3]$. However, a recent UK survey of human appendix tissue indicated that 493 (95\% confidence interval (CI): 282-801) per million people are asymptomatic carriers of the abnormal VCJD prion [4]. Control measures and trade restrictions imposed during the BSE epidemic resulted in devastating economic consequences for the British beef industry.

Scrapie is a prion disease that has been present in the sheep population in GB for several hundred years [5]. While there is no evidence linking scrapie to disease in humans, there have been concerns in the past that a scrapie outbreak could mask a hypothetical emergence of BSE in sheep. In addition, recent experimental studies using primate and humanised mouse models have indicated a zoonotic potential $[6,7]$. Cases of atypical scrapie and BSE have been detected in recent years, and their aetiologies remain unclear $[1,8]$. Atypical BSE occurs very rarely (only 10 cases have been detected to date in GB), while atypical scrapie appears to be endemic in $\mathrm{GB}$.

A number of measures aimed at the eradication of these transmissible spongiform encephalopathies (TSES) have been successful in that the incidence of both BSE and scrapie has fallen consistently in GB and across the European Union (EU) in recent years [1]. In order to determine the trend of TSE prevalence over time in EU Member States (MS), active surveillance is in place. This involves the testing for BSE in all EU MS of all cattle older than 48 months (24 months in some MS) which are either emergency-slaughtered for animal welfare reasons such as injury or illness or fallen stock which have died on the farm. Testing of healthy cattle slaughtered for human consumption was ceased in 2013 with certain exceptions (Bulgaria, Croatia and 


\section{FIGURE 1}

Key to interpretation of incremental cost effectiveness ratio plots

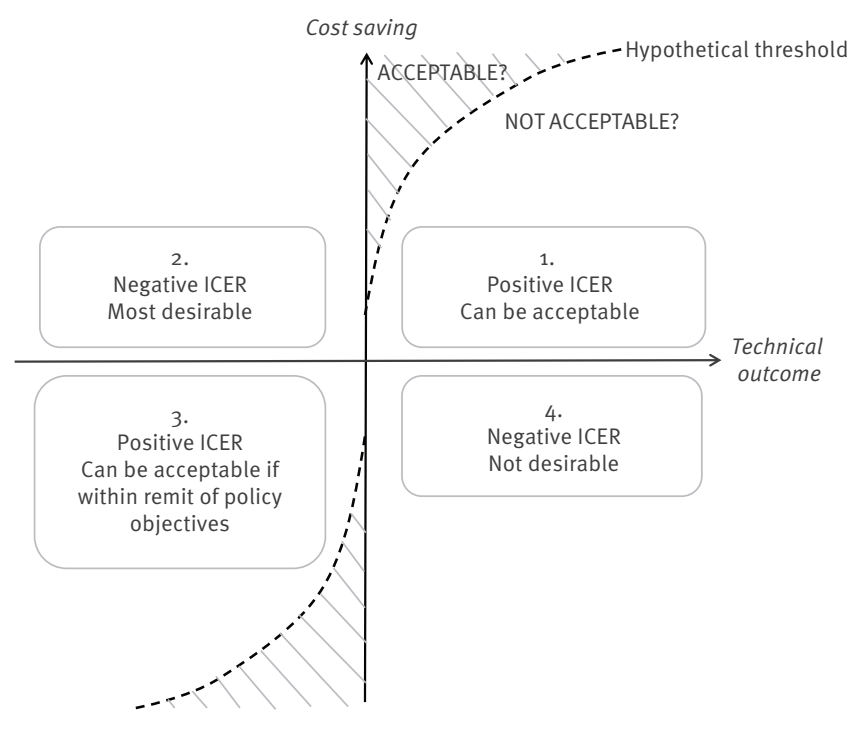

ICER: incremental cost effectiveness ratio.

ICERs with a positive value can fall within either quadrant 1 or 3 . Surveillance scenarios in quadrant 1 can be acceptable in terms of cost-effectiveness, if they are within a threshold of acceptability (to be defined by policymakers). Scenarios with ICER values in quadrant 3 are likely to be unsuitable for policy objectives. A negative ICER value could indicate either the most desirable result (quadrant 2), or an undesirable outcome (quadrant 4), hence care should be taken in interpretation.

Romania) for the EU-25 [9]. Passive surveillance is also carried out via the notification of suspect clinical cases by veterinary surgeons. For scrapie, active surveillance, in the form of an annual survey of both fallen stock and healthy slaughtered animals, was added in 2001 and started in 2002 for all EU MS to the compulsory notification of suspect clinical cases, to monitor the incidence in sheep and the impact of disease control measures [10]. The presence of atypical disease forms is also monitored as a by-product of active surveillance, but this is not its primary aim. In recent years, the ratio of detected cases over the number of animals tested for both BSE and scrapie has been very low. In 2014 for example, ca115,000 cattle were tested for BSE in GB, and just one case was detected [1]. There is therefore an economic incentive to re-evaluate current active surveillance systems to ensure that the resources deployed remain proportionate to the risk presented by a very low TSE prevalence. The re-allocation of funding could enable resources to be more effectively targeted at other diseases or issues, with beneficial outcomes for food safety. However, it is important that GB and the EU continue to have robust evidence to respond in a timely way to threats from new or re-emerging TSEs.

Previous studies have been conducted to evaluate BSE surveillance $[11,12]$. Most recently, to aid the determination of the level of sampling required, a model commissioned by the EU [13] demonstrated that a surveillance system based on the testing of at-risk animals (emergency slaughter, fallen stock and animals showing clinical signs) would be sufficient to detect a BSE case at a minimum prevalence of 1 in 100,000 in the standing population, with $95 \%$ confidence. However, this model was not able to explore the ability of such a surveillance system to detect re-emergence of birth cohort-based increases in BSE. For scrapie, models have focused on the estimation of prevalence of animals or holdings from surveillance data [14-16], rather than exploring the optimal design of a surveillance scheme.

The potential public health impact of TSEs and resulting political concern are important considerations in the formulation of surveillance strategies, and in situations where state or EU legislation apply, the research should be framed within this context. Animal health scientists have historically tended to focus on technical aspects of disease control without consideration of economic and socio-political impact [17]. Costeffectiveness analysis allows the consideration of the financial value of a change, framed by a measure of the impact that change may have on society. The aim of the present study was to evaluate the cost-effectiveness of alternative surveillance strategies for BSE and scrapie, while explicitly considering the policy implications of these changes.

\section{Methods}

The approach taken was firstly to simulate a number of BSE and scrapie surveillance scenarios and estimate the time taken to detect a statistically significant increasing trend in prevalence. Secondly, the total cost of surveillance between the start of the hypothetical increase and detection was calculated for each scenario. Thirdly, a number of measures for the technical assessment of surveillance were included in a costeffectiveness analysis of the alternative scenarios. Finally, a number of interviews were conducted with policy experts and key stakeholders to discuss the results and the future of TSE surveillance. Each of these steps is described below in greater detail.

\section{Estimating time to detect significant increasing trend}

The estimate of the prevalence in each birth cohort (BSE) or calendar year (scrapie) was obtained by means of the back-calculation approach used in Arnold and Wilesmith for BSE, and Arnold and OrtizPelaez for scrapie [11,14]. Information on population size, test sensitivity and numbers tested, along with the assumed trend of infection each year, was used to generate the number of expected and the number of observed cases each year in GB for each surveillance activity. Variability was determined by Poisson distribution, which was used to simulate the observed number of cases from the expected values. 


\section{FIGURE 2}

Incremental cost effectiveness ratios for alternative surveillance strategies for bovine spongiform encephalopathy, Great Britain

\section{A. Tine to detection}

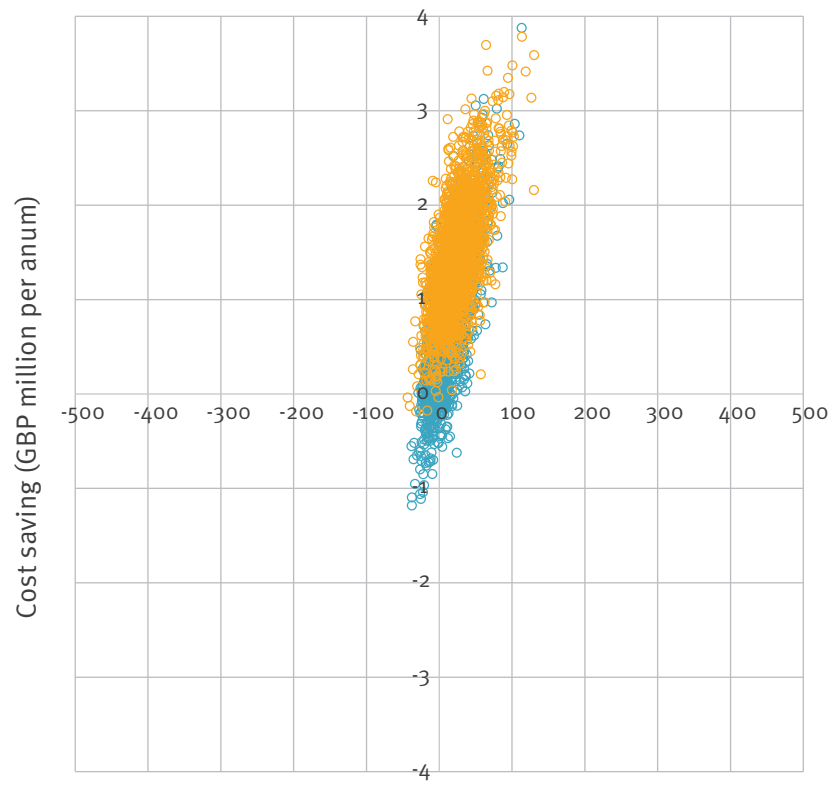

Relative change in time to detection (\%) compared to baseline

\section{Animals in standing population}

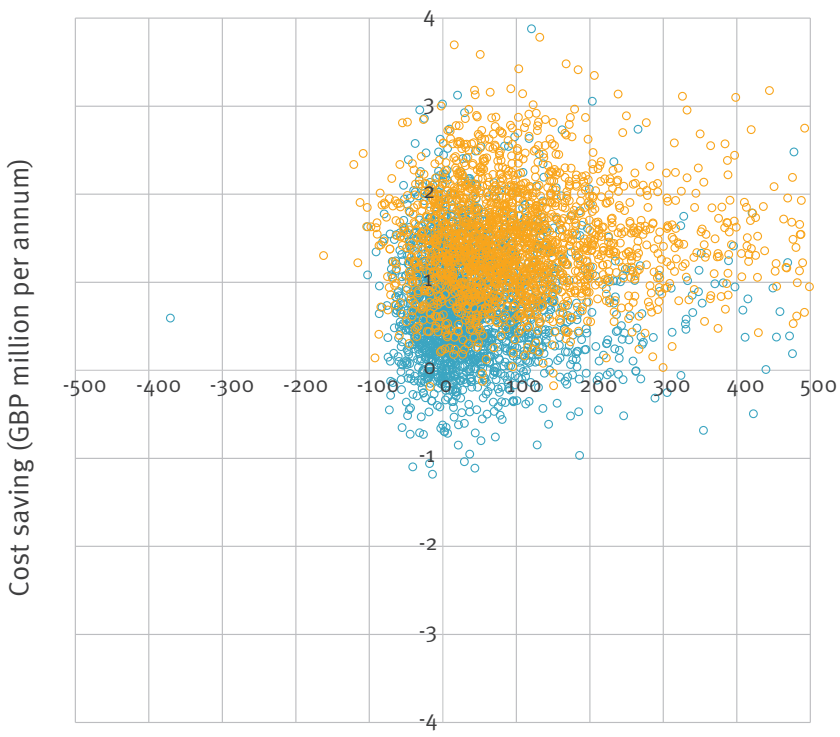

Relative change in the number of infected animals

\footnotetext{
in standing population (\%)
}

\section{B. Animals at slaughter}

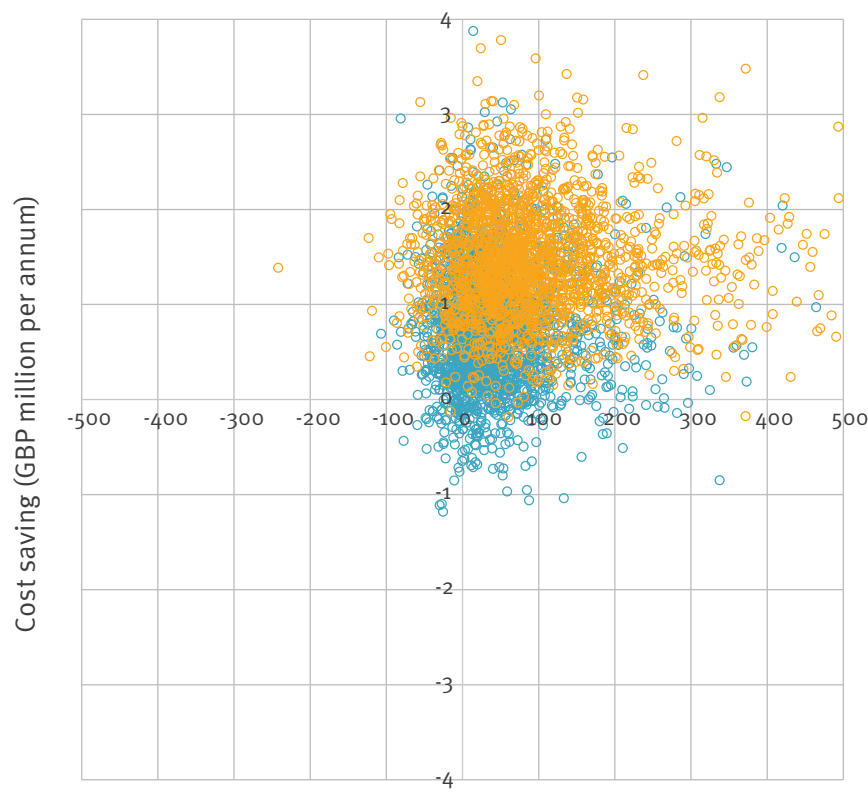

Relative change in the number of infected animals presented at slaughter (\%)

ICER: incremental cost effectiveness ratio.

Blue dots: strategies where $75 \%$ of fallen stock are tested; orange dots: strategies where $50 \%$ of fallen stock are tested. The spread of points indicates the range, i.e. the uncertainty associated with the ICER, and is derived from 1,000 iterations of the model. For clarity, only scenarios involving the highest and the lowest starting point and rate of increase in prevalence are displayed (i.e. scenarios 2, 3, 17 and 18). 


\section{FIGURE 3}

Incremental cost effectiveness ratio values for alternative scrapie surveillance scenarios, in relation to the number of years until detection of an increasing trend, Great Britain

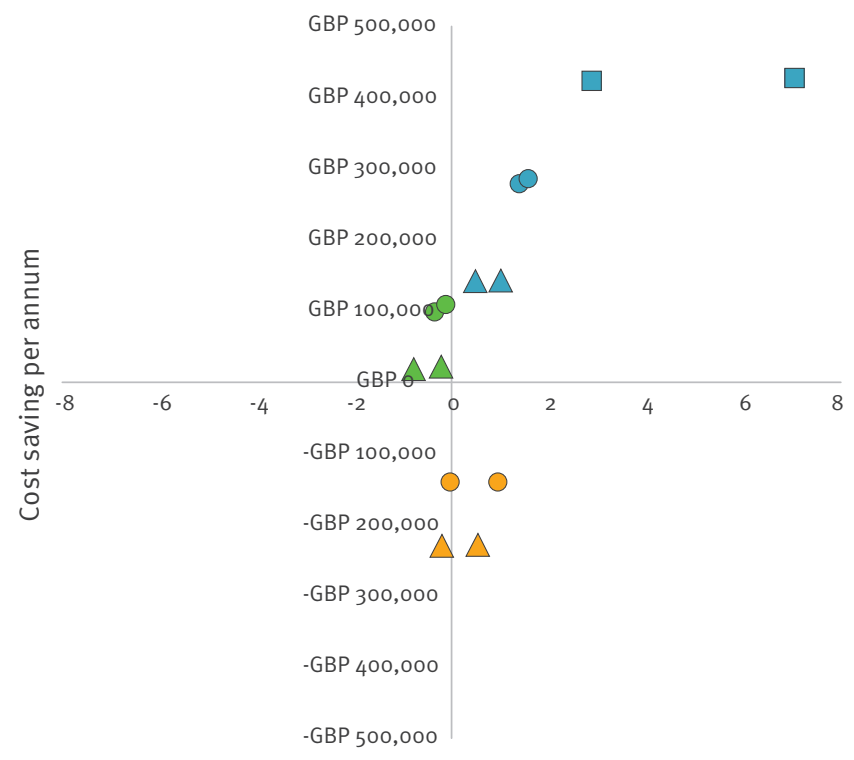

Change in the number of years to detection
$\triangle$ Strategy 1
Strategy 3
Strategy 5
Strategy 7
Strategy 2
$\triangle$ Strategy 4
$\triangle$ Strategy 6

Strategies 1-3: changing the total number of animals sampled; strategies 4-5: increasing the ratio of abattoir survey to fallen stock tested; strategies 6-7: reducing the ratio of abattoir survey to fallen stock tested. For each strategy, scenarios involving $10 \%$ and $5 \%$ hypothetical rates of increase in prevalence are plotted.

To estimate the time of detection, a model of the form $A \exp (B t)$ was used (where $A$ represents the infection prevalence at the start of the re-emergence, $B$ represents the annual rate of increase, and exp denotes exponential growth), fitted to the infection prevalence in each birth cohort (BSE) or calendar year (scrapie), from the time when the prevalence started to increase. The first time point at which the rate of increase was statistically significant was recorded. The model was run 100 times for each scenario.

The scenarios to be modelled were defined during a stakeholder workshop involving policymakers from the Department for the Environment, Food and Rural Affairs (Defra), the Animal and Plant Health Agency (APHA) and the Food Standards Agency (FSA), UK government bodies which are concerned with food safety and/or livestock health. Scenarios modelled for BSE involved:

- i) the proportion of fallen stock tested: $100 \%$ (baseline), $75 \%$ and $50 \%$

- ii) the hypothetical rate of increase in birth cohort prevalence: $40 \%, 20 \%$ and $10 \%$

\section{FIGURE 4}

Distributions of incremental cost effectiveness ratio values for alternative scrapie surveillance scenarios, in relation to the number of years until detection of an increasing trend, Great Britain

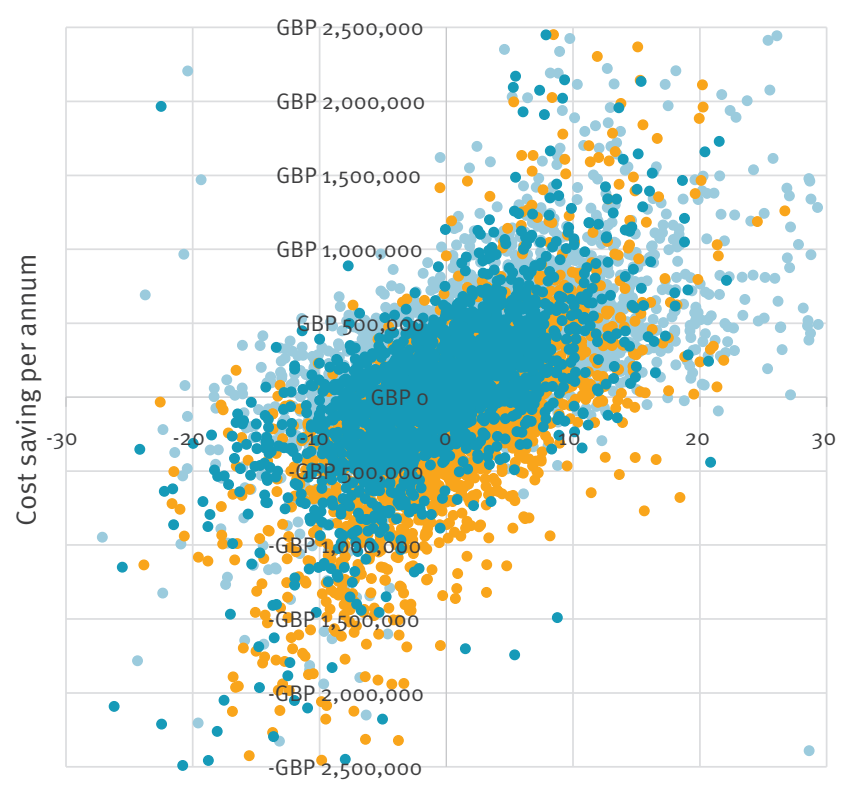

Change in the number of years to detection

Blue dots: scenarios 1-3; orange dots: scenarios 4-5; purple dots: scenarios 6-7. Only 500 iterations of the model are shown, for clarity.

- iii) the age of cattle tested:>48 months (baseline), $>60$ months and $>72$ months

- iv) the starting point: 2006 (relatively high prevalence) and 2013 (very low prevalence)

For scrapie, scenarios were based on:

- i) the annual number of sheep tested: 20,000 (baseline), 15,000, 10,000 and 5,000

- ii) the ratio of abattoir survey sheep versus fallen stock sheep tested: 33:76 (baseline), 100:0, 75:25, 25:75 and 0:100

- iii) the hypothetical annual increase in standing population prevalence: $10 \%$ and $5 \%$

At the same workshop, parameters to measure the technical effectiveness of surveillance were also decided by policy stakeholders. These were:

- $\mathrm{i}$ the time to detection of an increasing trend in prevalence

- ii) the number of infected animals (and sheep holdings for scrapie) in the standing population at the time of detection 
TABLE 1

Simulated technical outcomes (including 95\% confidence intervals) and costs of scenarios for the surveillance of bovine spongiform encephalopathy, Great Britain

\begin{tabular}{|c|c|c|c|c|c|c|c|}
\hline \multirow[t]{2}{*}{ Scenario } & \multirow[t]{2}{*}{$\begin{array}{l}\text { Starting } \\
\text { point }\end{array}$} & \multirow[t]{2}{*}{$\begin{array}{l}\text { Rate of annual } \\
\text { increase in } \\
\text { prevalence (\%) }\end{array}$} & \multirow[t]{2}{*}{$\begin{array}{l}\text { \% fallen stock tested } \\
\text { (> } 48 \text { months) }\end{array}$} & $\begin{array}{l}\text { Years until } \\
\text { detection of } \\
\text { an increase } \\
\text { in prevalence }\end{array}$ & $\begin{array}{l}\text { Infected animals } \\
\text { presented } \\
\text { at slaughter } \\
\text { during period } \\
\text { to detection }\end{array}$ & $\begin{array}{l}\text { Infected animals } \\
\text { in UK standing } \\
\text { population at time } \\
\text { of detection }\end{array}$ & \multirow[t]{2}{*}{$\begin{array}{c}\text { Mean } \\
\text { annual cost } \\
\text { in million } \\
\text { GBP }\end{array}$} \\
\hline & & & & Mean (SD) & Mean (SD) & Mean (SD) & \\
\hline 1 & 2006 & 40 & 100 & $7.61(+/-1.76)$ & $111(+/-59)$ & $260(+/-152)$ & 2.86 \\
\hline 2 & 2006 & 40 & 75 & $8.07(+/-1.79)$ & $131(+/-80)$ & $305(+/-194)$ & 2.15 \\
\hline 3 & 2006 & 40 & 50 & $8.68(+/-2.32)$ & $162(+/-126)$ & $385(+/-305)$ & 1.43 \\
\hline 4 & 2006 & 20 & 100 & $8.37(+/-2.13)$ & $67(+/-25)$ & $74(+/-16)$ & 2.87 \\
\hline 5 & 2006 & 20 & 75 & $8.37(+/-2.39)$ & $85(+/-43)$ & $126(+/-56)$ & 2.14 \\
\hline 6 & 2006 & 20 & 50 & $9.62(+/-3.14)$ & $112(+/-71)$ & $160(+/-92)$ & 1.44 \\
\hline 7 & 2006 & 10 & 100 & $8.36(+/-2.16)$ & $66(+/-25)$ & $74(+/-15)$ & 2.86 \\
\hline 8 & 2006 & 10 & 75 & $9.12(+/-2.85)$ & $77(+/-36)$ & $79(+/-22)$ & 2.14 \\
\hline 9 & 2006 & 10 & 50 & $10.57(+/-4.92)$ & $95(+/-67)$ & $89(+/-33)$ & 1.42 \\
\hline 10 & 2013 & 40 & 100 & $14.97(+/-3.21)$ & $88(+/-61)$ & $70(+/-25)$ & 2.87 \\
\hline 11 & 2013 & 40 & 75 & $21.09(+/-2.77)$ & $116(+/-74)$ & $64(+/-2)$ & 2.14 \\
\hline 12 & 2013 & 40 & 50 & $22.40(+/-2.62)$ & $166(+/-122)$ & $53(+/-27)$ & 1.43 \\
\hline 13 & 2013 & 20 & 100 & $21.35(+/-3.61)$ & $71(+/-36)$ & $66(+/-44)$ & 2.85 \\
\hline 14 & 2013 & 20 & 75 & $22.76(+/-3.57)$ & $86(+/-44)$ & $86(+/-58)$ & 2.14 \\
\hline 15 & 2013 & 20 & 50 & $26.09(+/-3.92)$ & $137(+/-78)$ & $159(+/-103)$ & 1.43 \\
\hline 16 & 2013 & 10 & 100 & $32.42(+/-9.25)$ & $74(+/-47)$ & $39(+/-32)$ & 2.85 \\
\hline 17 & 2013 & 10 & 75 & $36.59(+/-5.72)$ & $104(+/-21)$ & $55(+/-30)$ & 2.14 \\
\hline 18 & 2013 & 10 & 50 & $42.23(+/-5.25)$ & $147(+/-68)$ & $93(+/-47)$ & 1.43 \\
\hline 19 & 2006 & 40 & $100 \%>60$ months & $8.58(+/-2.06)$ & $153(+/-103)$ & $366(+/-249)$ & 2.43 \\
\hline 20 & 2006 & 40 & $100 \%>72$ months & $10.15(+/-2.24)$ & $261(+/-189)$ & $623(+/-449)$ & 2.03 \\
\hline
\end{tabular}

SD: standard deviation; UK: United Kingdom.

- iii) the number of infected animals presented at slaughter during the period from the start of the increasing trend to detection.

\section{Costing of core surveillance activities}

The costs of TSE surveillance were considered from a public sector perspective. The approach was to calculate the variable cost of testing one fallen stock cow, one fallen stock sheep or one abattoir sheep in GB, taking into account the following surveillance activities: The cost of rapid testing (all animals), including: (i) sampling and administration costs at the sampling site, (ii) consumables for sampling, (iii) sending of samples by courier from the sampling site to the laboratory, and (iv) rapid testing at the laboratory. In the case of a positive or equivocal result on the rapid test, in addition: (i) transportation from the laboratory to the APHA and (ii) confirmatory testing. Fixed costs (such as sample archiving) were assumed not to change with respect to the number of animals tested and thus were not included in the analysis.

\section{Estimating cost-effectiveness}

The costs of each surveillance scenario were obtained by stochastic simulation using @RISK 6 software [18].
The unit cost of testing one animal was multiplied by the number of animals tested per year and the number of years until detection of a statistically significant increasing trend in prevalence. To account for variability, a normal distribution was applied to the number of years until detection, using the mean and standard deviation (SD) values generated from the simulation model. There was variability in the cost of sample transportation, and this was incorporated into the model as a normal distribution using the mean and SD of quotes from several different couriers. The predicted number of detected cases, as well as the number of false-positive or equivocal results expected based on the specificity of the rapid test, were used to calculate the cost of confirmatory testing during the period. The simulation was run for 1,000 iterations. As costs over time were linear, the cost per annum was derived from the cumulative cost of each scenario.

The number of infected animals in the standing population at the time of detection was calculated using the simulated prevalence of infection at the time of detection and the most recent available UK cattle and sheep population data (from 2013) [19]. The number 
Costs and simulated technical outcomes (including 95\% confidence intervals) of various surveillance scenarios for classical scrapie, Great Britain

\begin{tabular}{|c|c|c|c|c|c|c|c|c|}
\hline & \multicolumn{3}{|c|}{$\begin{array}{l}\text { Abattoir survey and fallen stock } \\
\text { sampling scheme }\end{array}$} & \multirow{2}{*}{$\begin{array}{l}\text { Years to detection } \\
\text { Mean (SD) }\end{array}$} & \multirow{2}{*}{$\begin{array}{l}\text { Mean no. } \\
\text { of infected } \\
\text { animals } \\
\text { presented } \\
\text { at slaughter } \\
\text { before } \\
\text { detection }\end{array}$} & \multirow{2}{*}{$\begin{array}{l}\text { Mean no. } \\
\text { of infected } \\
\text { animals in } \\
\text { standing } \\
\text { population at } \\
\text { detection }\end{array}$} & \multirow{2}{*}{$\begin{array}{l}\text { Mean no. } \\
\text { of infected } \\
\text { holdings } \\
\text { at time of } \\
\text { detection }\end{array}$} & \multirow[b]{2}{*}{$\begin{array}{l}\text { Mean } \\
\text { annual } \\
\text { cost in } \\
\text { GBP }\end{array}$} \\
\hline & Scenario & $\begin{array}{l}\text { Total } \\
\text { no. of } \\
\text { animals } \\
\text { tested } \\
\text { per year }\end{array}$ & $\begin{array}{l}\text { AS:FS } \\
\text { ratio }\end{array}$ & & & & & \\
\hline \multirow{8}{*}{$\begin{array}{l}10 \% \text { annual rate } \\
\text { of increase in } \\
\text { prevalence }\end{array}$} & Baseline & 20,000 & $33: 67$ & $11.19(+/-6.17)$ & 2,100 & 29,411 & 712 & 565,637 \\
\hline & 1 & 15,000 & $33: 67$ & $11.68(+/-7.30)$ & 2,311 & 31,674 & 748 & 423,309 \\
\hline & 2 & 10,000 & $33: 67$ & $12.58(+/-7.59)$ & 2,631 & 36,198 & 819 & 285,738 \\
\hline & 3 & 5,000 & $33: 67$ & $14.07(+/-8.61)$ & 3,278 & 40,723 & 961 & 141,932 \\
\hline & 4 & 20,000 & 100:0 & $11.73(+/-6.62)$ & 2,266 & 31,674 & 748 & 793,899 \\
\hline & 5 & 20,000 & $75: 25$ & $11.16(+/-7.22)$ & 2,122 & 31,674 & 748 & 705,796 \\
\hline & 6 & 20,000 & $25: 75$ & $10.41(+/-6.90)$ & 1,914 & 29,411 & 641 & 546,633 \\
\hline & 7 & 20,000 & $0: 100$ & $10.84(+/-6.48)$ & 2,029 & 29,411 & 677 & 466,698 \\
\hline \multirow{8}{*}{$\begin{array}{l}5 \% \text { annual rate } \\
\text { of increase in } \\
\text { prevalence }\end{array}$} & Baseline & 20,000 & $33: 67$ & $16.18(+/-12.73)$ & 2,594 & 22,624 & 534 & 568,968 \\
\hline & 1 & 15,000 & $33: 67$ & $17.19(+/-14.14)$ & 2,875 & 24,886 & 570 & 425,387 \\
\hline & 2 & 10,000 & $33: 67$ & $17.74(+/-15.55)$ & 3,082 & 24,886 & 570 & 282,690 \\
\hline & 3 & 5,000 & $33: 67$ & $23.23(+/-17.32)$ & 4,719 & 33,936 & 783 & 141,369 \\
\hline & 4 & 20,000 & 100:0 & $15.98(+/-12.23)$ & 2,501 & 22,624 & 534 & 798,568 \\
\hline & 5 & 20,000 & $75: 25$ & $17.13(+/-11.74)$ & 2,744 & 24,886 & 534 & 709,465 \\
\hline & 6 & 20,000 & $25: 75$ & $15.98(+/-12.38)$ & 2,532 & 22,624 & 534 & 546,842 \\
\hline & 7 & 20,000 & $0: 100$ & $16.06(+/-10.00)$ & 2,494 & 22,624 & 499 & 460,393 \\
\hline
\end{tabular}

AS: abattoir survey; FS: fallen stock; SD: standard deviation.

of infected sheep holdings in the standing population was estimated using UK data from 2010 [20].

In order to compare the cost-effectiveness of different surveillance scenarios, incremental cost effectiveness ratios (ICERs) were calculated as per Formula 1.

\section{Formula 1}

$$
\mathrm{ICER}=\frac{-\left(C_{a}-C_{b}\right)}{\left(O_{a}-O_{b}\right)} / 1,000
$$

where $C=$ cost; $O=$ outcome; $a=$ alternative surveillance scenario and $b=$ baseline scenario.

This provided an explicit expression of the difference in cost of an alternative scenario compared with the baseline, taking into account the difference in technical outcomes [21]. Using negative cost in this equation means that this ICER is a measure of money saved rather than money spent. ICER results are displayed in plots of costs saved against technical outcomes. Figure 1 shows a key to interpretation of ICER plots.

\section{Policy perspective}

Finally, cost-effectiveness results were presented to policy stakeholders during a second workshop and telephone and email interviews were conducted with 15 experts in TSE science and policy from Defra, APHA, FSA, the European Food Safety Authority (EFSA), the European Commission, and higher education and research institutions. These semi-structured interviews explored stakeholders' views on the purpose and future direction of surveillance, and the political landscape including trade and the public.

\section{Results}

Bovine spongiform encephalopathy

Table 1 summarises the simulation results for each scenario.

Reducing the proportion of fallen stock tested resulted in considerable reductions in the annual cost of surveillance. However, it also had an impact on the effectiveness of surveillance, increasing the number of years until detection of an increasing trend in prevalence, the number of infected animals in the standing population at the time of detection and the number of infected animals presented at slaughter before detection (Table 1). The magnitude of this effect varied depending on the starting point and the rate of hypothetical increase in prevalence.

The ICER plots in Figure 2 show the distribution of the simulation results, derived from 1,000 iterations of 
the model. These plots demonstrated that strategies testing $75 \%$ or $50 \%$ of fallen stock may be considered acceptable in terms of cost-effectiveness, as their distributions fell mainly within quadrant 1 . Strategies where $50 \%$ of fallen stock are tested provided a mean cost saving of GBP 1.43 million per annum, around twice the cost saving of strategies testing $75 \%$ of fallen stock (mean cost saving GBP 716,000 per annum). The distribution of values shown in Figure 2 reflects inherent variability and uncertainty in both the costs and technical outcomes, which were taken into account in the model.

Mean ICER values for $75 \%$ and $50 \%$ testing strategies were, respectively: GBP 667,000 and 628,000 (saved per additional year to detection), GBP 40,000 and 28,000 (saved per additional infected animal presented at slaughter during the period to detection), and GBP 20,000 and 14,000 (saved per additional infected animal in the standing population at detection). The lower ICER values indicated that 50\% testing strategies are less cost-effective in terms of every technical outcome modelled. However, given the establishment of a threshold of acceptability (as per Figure 1) they could potentially still be considered acceptable in terms of cost-effectiveness, and therefore adopted into policy, which would enable considerable cost savings.

Increasing the age at which fallen stock animals are tested performed less favourably than reducing the proportion of fallen stock tested in terms of cost-effectiveness (Table 1 ).

\section{Scrapie}

Reducing the total number of sheep tested without changing the ratio of abattoir survey to fallen stock (i.e. scenarios 1-3 in Table 2) increased the time to detection of an increasing trend of scrapie prevalence by between $4.4 \%$ and $25.7 \%$, or between $6.2 \%$ and $43.6 \%$ at a $10 \%$ or $5 \%$ rate of increase in prevalence, respectively (Table 2 ), along with similar proportionate increases in the number of infected animals and the number of infected holdings in the population at detection.

When the mean model outputs for these strategies were plotted, they all fell within quadrant 1 (Figure 3), indicating that they can be considered to be cost-effective relative to the baseline depending on the threshold of acceptability. The mean ICERs for one of the technical outcomes (the number of years to detection) are shown in Figure 3 as an example. Figure 4 demonstrates the variation associated with these mean values, showing the distribution of results of multiple iterations of the model.

Table 2 shows that changing the proportion of abattoir survey animals to fallen stock (scenarios 4-7) had a small influence on the mean number of years to detection as well as the other technical outcomes, but had a considerable impact on cost. The mean ICER values for all three technical outcomes (an example is shown in Figure 3) indicate that strategies which involve reducing the proportion of sheep tested in the abattoir survey (strategies 6 and 7) were the most cost-effective of all strategies modelled, as they were all located within the second (most desirable) and first quadrants. However, the distribution of simulation results for one of the technical outcomes - the number of years to detection (Figure 4) - shows that there are a large range of possible outcomes (note the difference in scale between Figures 3 and 4), some of which fall into the third quadrant. Outcomes in the third quadrant are not desirable in the context of the policy question addressed by the present study.

For all scenarios, the starting prevalence in animals was 0.00044 (ca 7,400 infected sheep), so there was a three- to four-fold increase in the prevalence in animals at detection depending on the scenario. The prevalence of infected flocks before the increasing trend was 0.0064 (ca 460 flocks), so there was a 2.8- to 3.6-fold increase in the prevalence of infected flocks at detection, depending on the scenario.

A reduction in the rate of prevalence increase from $10 \%$ to $5 \%$ across scenarios caused an increase in the mean time to detection (Table 2). However, the final prevalence of infected sheep and holdings was on average lower for the $5 \%$ increase per annum compared with the $10 \%$ increase.

\section{Policy}

Some of the 15 experts who were interviewed were cautious about the idea of reducing BSE and scrapie surveillance, expressing that active surveillance plays a role in building trust with other countries in order to strengthen trade. Nonetheless, there were indications of some interest in a change in active surveillance. It is most likely that a reduction in BSE surveillance would be considered only if and when the UK achieves 'negligible risk' status by EU and World Organisation for Animal Health (OIE) standards. There were mixed views among experts as to what would be the potential impact on trade (if any) of reducing scrapie surveillance, and there is already some policy support for changing the ratio of sheep tested in favour of fallen stock.

\section{Discussion}

Surveillance for BSE across the EU has been evaluated in terms of its ability to detect a test-positive animal at a minimum prevalence of 1 in 100,000 in the standing population with $95 \%$ confidence [22], and on this basis recommendations were made that healthy slaughtered cattle no longer need to be tested. While the calculations were rigorous, the choice of the target minimum prevalence is debatable and represents a balance between having a robust surveillance system and what is practical in terms of cost. Our study builds on this work firstly by providing a more thorough evaluation of the ability of a surveillance system to detect 
re-emergence, and secondly by linking the surveillance measures to cost. While this study uses data from GB, the model could easily be applied to data from other European countries in future analyses.

The model for BSE surveillance is dependent on assumptions regarding the age of onset, which was estimated using data from the original BSE outbreak [23] but could feasibly have changed in more recent cases. Analysis of animals born after the reinforced feed ban (BARBs) in GB (in July 1996) has shown that the age of onset has not changed significantly for BARBs compared with animals born before the total feed ban [24], although there are few BSE-infected BARB animals (150 in GB) compared with pre-BARB BSE cases (approximately 180,000 in GB). A lengthening of the incubation period, for example because of a lower average infectious dose, would make the time to detection longer than that predicted in the present study, although the incubation period is not sensitive to small changes in dose [25].

The approach for modelling scrapie surveillance was based on assumptions of an annual increase in scrapie prevalence in the standing population, whereas the approach used for BSE in this study was based on an increase in successive birth cohorts. For scrapie, estimation of prevalence in birth cohorts is problematic because the age of the tested animals is not recorded. The present model only considered an increase in the prevalence of classical scrapie, as that was deemed of much greater relevance to policy than an increase in atypical scrapie. The model framework developed in the present study could be adapted for use for atypical scrapie, although there are likely to be difficulties in estimating some of the necessary parameters, particularly the sensitivity of the rapid test. We found that if the proportion of sheep tested in the abattoir stream were reduced, there would be a reduction in the cost of surveillance while maintaining technical outcomes. However, EU approval would currently be required for such a change.

In addition to modelling the technical outcomes, the present study also links these with costs in the form of the ICER. The costs of each scenario were calculated for the hypothetical outbreak period only (i.e. from the start of an increasing trend in prevalence until detection), even though surveillance is continuous, as this enabled comparison between scenarios. It is useful for policymakers to identify a threshold of acceptability for ICERs. Standardised ICER thresholds are established in human healthcare settings $[26,27]$ and help policymakers to decide upon whether a proposed scheme is appropriately cost-effective or not. In this case, policymakers would need to consider at what point a compromise in technical effectiveness becomes unacceptable, and whether this varies according to costs saved.

A considerable proportion of the simulation results for scrapie were located in the third quadrant, in which technical outcomes are improved given an increase in costs. This is a result of random variation, arising from the variability and uncertainty incorporated into the model. Outcomes in the third quadrant may technically be considered cost-effective but are not desirable from a policy perspective, given that the objective of the present study was to explore ways to reduce the cost of surveillance. This highlights that the mean ICER values should be carefully considered within the context of the range of possible outcomes.

Before active surveillance was implemented, passive surveillance was useful for detecting BSE cases during the early stages of the epidemic in the UK. However, since the decline in BSE cases, passive surveillance has become less useful, as it depends greatly on the vigilance of farmers and veterinarians and their ability to recognise clinical signs, which will naturally decline with increasing time since an epidemic. It could be hypothesised that in the future, active surveillance may eventually be replaced with a different approach, for example risk-based surveillance, but such a change would still need to be consistent with the regulatory framework.

TSE surveillance is part of a package of control measures, including the restricted feed ban which prohibits feeding mammalian meat and bone meal to livestock and the removal of specified risk material in abattoirs [28]. Consumers would continue to be protected by these controls regardless of any change in surveillance strategy.

Two of the TSE experts interviewed suggested to raise the age of fallen stock tested for BSE from the current 48 months. However, the present study found this to be a considerably less cost-effective strategy than reducing the proportion of fallen stock tested. This highlights the value of studies such as this to provide a robust basis on which experts can form opinions. Ultimately, a strong base of scientific evidence should underpin any future changes to TSE policy.

\section{Acknowledgements}

Kathryn Woolaway (Defra), Jim Hope (Animal and Plant Health Agency), Daniel Adipke (Defra), Ravi Nagrath (Defra), Katie Barnes (Defra), Marion Simmons (Defra), Amie Adkin (Animal and Plant Health Agency).

The study was funded by the UK Department for Environment, Food and Rural Affairs.

The study was approved by the Royal Veterinary College's Clinical Research Ethical Review Board. Interviewees provided informed consent to participate in the study and for the publication of this article.

\section{Conflict of interest}

None declared. 


\section{Authors' contributions}

Mark Arnold produced the epidemiological models. Devi Radia and Ben Wall performed the costing of surveillance activities. Ben Wall developed the economic model. Devi Radia conducted telephone and email interviews with policy experts. Will Gilbert advised on the development of the economic model. Angel Ortiz-Pelaez gave advice regarding TSEs and TSE surveillance. Ed Van Klink and Katharina Stäerk provided guidance concerning policy implementation. Javier Guitian conceived and supervised the study. All authors contributed to the drafting the article, and final approval of the version to be published.

\section{References}

1. Animal and Plant Health Agency (APHA). Active disease surveillance: TSE statistics. Addlestone: APHA; 2015. Available from: https://www.gov.uk/government/statistics/ active-tse-surveillance-statistics

2. National CJD Research and Surveillance Unit (NCJDRSU). Latest CJD figures. Edinburgh: NCJDRSU; 2015. Available from: http:// www.cjd.ed.ac.uk/data-and-reports/latest-cjd-figures

3. Maheshwari A, Fischer M, Gambetti P, Parker A, Ram A, Soto $C$, et al. Recent US Case of Variant Creutzfeldt-Jakob DiseaseGlobal Implications. Emerg Infect Dis. 2015;21(5):750-9. DOI: 10.3201/eid2105.142017 PMID: 25897712

4. Gill ON, Spencer Y, Richard-Loendt A, Kelly C, Dabaghian R, Boyes $\mathrm{L}$, et al. Prevalent abnormal prion protein in human appendixes after bovine spongiform encephalopathy epizootic: large scale survey. BMJ. 2013;347(oct15 5):f5675. DOI: 10.1136/ bmj.f5675 PMID: 24129059

5. Detwiler LA. Scrapie.Rev Sci Tech. 1992;11(2):491-537. DOI: 10.20506/rst.11.2.607 PMID: 1617202

6. Cassard H, Torres JM, Lacroux C, Douet JY, Benestad SL, Lantier $\mathrm{F}$, et al. Evidence for zoonotic potential of ovine scrapie prions. Nat Commun. 2014;5:5821. DOI: 10.1038/ncomms6821 PMID: 25510416

7. Comoy EE, Mikol J, Luccantoni-Freire S, Correia E, LescoutraEtchegaray N, Durand V, et al. Transmission of scrapie prions to primate after an extended silent incubation period. Sci Rep. 2015;5(1):11573. DOI: 10.1038/srep11573 PMID: 26123044

8. World Organisation for Animal Health (OIE). Number of cases of bovine spongiform encephalopathy (BSE) reported in the United Kingdom. Paris: OIE; 2015. Available from: http://www. oie.int/en/animal-health-in-the-world/bse-specific-data/ number-of-cases-in-the-united-kingdom/

9. BSE surveillance requirements. Edinburgh: Scottish Government; [Accessed: 5 Nov 2015]. Available from: http://www.gov.scot/Topics/farmingrural/Agriculture/ animal-welfare/Diseases/disease/bse/advice/testing

10. Animal and Plant Health Agency (APHA). Sheep and goats: scrapie disease surveillance. Addlestone: APHA; 2014. Available from: https://www.gov.uk/government/statistics/ sheep-and-goats-scrapie-disease-surveillance

11. Arnold M, Wilesmith J. Modelling studies on bovine spongiform encephalopathy occurrence to assist in the review of the over 30 months rule in Great Britain.Proc Biol Sci. 2003;270(1529):2141-5. DOI: 10.1098/rspb.2003.2494 PMID: 14561277

12. Prattley DJ, Morris RS, Cannon RM, Wilesmith JW, Stevenson MA. A model (BSurvE) for evaluating national surveillance programs for bovine spongiform encephalopathy.Prev Vet Med. 2007;81(4):225-35. DOI: 10.1016/j.prevetmed.2007.03.006 PMID: 17517443

13. Adkin A, Simmons R, Arnold M. Final report on a model for the evaluation of different options for the monitoring of transmissible encephalopathies in cattle in the European union (C-TSEMM). EFSA J. 2012;9(10):EN-349. [55 pp.]. doi: DOI: 10.2903/sp.efsa.2012.EN-349

14. Arnold M, Ortiz-Pelaez A. The evolution of the prevalence of classical scrapie in sheep in Great Britain using surveillance data between 2005 and 2012.Prev Vet Med. 2014;117(1):242-50. DOI: 10.1016/j.prevetmed.2014.07.015 PMID: 25183633

15. Gubbins S. Prevalence of sheep infected with classical scrapie in Great Britain: integrating multiple sources of surveillance data for 2002.J R Soc Interface. 2008;5(28):1343-51. DOI: 10.1098/rsif.2008.0021 PMID: 18348959

16. Del Rio Vilas VJ, Böhning D. Application of one-list capturerecapture models to scrapie surveillance data in Great Britain.Prev Vet Med. 2008;85(3-4):253-66. DOI: 10.1016/j. prevetmed.2008.02.003 PMID: 18355934
17. Boqvist S, Dekker A, Depner K, Grace D, Hueston W, Stärk KD, et al. Contagious animal diseases: the science behind trade policies and standards. Vet J. 2014;202(1):7-10. DOI: 10.1016/j. tvjl.2014.06.020 PMID: 25168718

18. @Risk version 6.o. Ithaca, NY: Palisade Corporation; 2014. Available from: http://www.palisade.com/risk/

19. Farming statistics - livestock populations at 1 December 2013 , United Kingdom. York: Department for Environment Food and Rural Affairs; 2014. Available from: https://www.gov. uk/government/uploads/system/uploads/attachment_data/ file/293717/structure-dec2013-uk-19mar14.pdf

20. Structure of the agricultural industry in England and the UK at June. York: Department for Environment Food and Rural Affairs; 2010. Available from: https://www.gov.uk/government/ statistical-data-sets/structure-of-the-agricultural-industry-inengland-and-the-uk-at-june

21. Garber AM, Phelps CE. Economic foundations of costeffectiveness analysis.J Health Econ. 1997;16(1):1-31. DOI: 10.1016/S0167-6296(96)00506-1 PMID: 10167341

22. European Food Safety Authority (EFSA). Scientific and technical assistance on the minimum sample size to test should an annual BSE statistical testing regime be authorised in healthy slaughtered cattle.EFSA J. 2012;10(10):2913. DOI: 10.2903/j. efsa.2012.2913

23. Arnold ME, Wilesmith JW. Estimation of the age-dependent risk of infection to BSE of dairy cattle in Great Britain.Prev Vet Med. 2004;66(1-4):35-47. DOI: 10.1016/j.prevetmed.2004.07.007 PMID: 15579333

24. Wilesmith JW, Ryan JB, Arnold ME, Stevenson MA, Burke PJ. Descriptive epidemiological features of cases of bovine spongiform encephalopathy born after July 31, 1996 in Great Britain.Vet Rec. 2010;167(8):279-86. DOI: 10.1136/vr.c4552 PMID: 20729514

25. Wells GAH, Konold T, Arnold ME, Austin AR, Hawkins SAC, Stack $M$, et al. Bovine spongiform encephalopathy: the effect of oral exposure dose on attack rate and incubation period in cattle. J Gen Virol. 2007;88(Pt 4):1363-73. DOI: 10.1099/ vir.0.82421-o PMID: 17374783

26. Gafni A, Birch S. Incremental cost-effectiveness ratios (ICERs): the silence of the lambda.Soc Sci Med. 2006;62(9):2091-100. DOI: 10.1016/j.socscimed.2005.10.023 PMID: 16325975

27. McCabe C, Claxton K, Culyer AJ. The NICE cost-effectiveness threshold: what it is and what that means.Pharmacoeconomics. 2008;26(9):733-44. DOI: 10.2165/00019053-20082609000004 PMID: 18767894

28. Control of TSEs (including BSE and scrapie). Brussels: European Commission. [Accessed: 24 Apr 2015]. Available from: http://ec.europa.eu/food/food/biosafety/tse_bse/ feed_ban_en.htm

\section{License and copyright}

This is an open-access article distributed under the terms of the Creative Commons Attribution (CC BY 4.0) Licence. You may share and adapt the material, but must give appropriate credit to the source, provide a link to the licence, and indicate if changes were made.

This article is copyright of the authors, 2017. 